\title{
Non-hierarchical Collaboration in Dynamic Business Communities
}

\author{
A.H.M. Shamsuzzoha ${ }^{1}$, Timo Kankaanpaa ${ }^{1}$, Petri Helo ${ }^{1}$, Luis Maia Carneiro ${ }^{2}$, \\ Ricardo Almeida ${ }^{2}$, and Rosanna Fornasiero ${ }^{3}$ \\ ${ }^{1}$ University of Vaasa, Finland \\ ${ }^{2}$ INESC Porto, Portugal \\ ${ }^{3}$ CNR-ITIA, Italy \\ ahsh@uwasa.fi
}

\begin{abstract}
A business community where communication can be streamlined, information shared and trust can be built can be considered as a collaborative network promoting SMEs long term sustainability by assuring quick response, fast time to market, differentiated offerings and competitive prices. This collaboration could be orchestrated both in hierarchical and non-hierarchical forms depending on the firms size, capacity and objectives. In this research, we have considered non-hierarchical networking among firms, especially for small and medium sized enterprises (SMEs), where the basic requirements are related with choosing appropriate business partners, building trust and sharing valuable information among them. In order to articulate the concept of this nonhierarchical collaboration, six pilot SMEs were analyzed and a methodological approach to manage these environments is proposed. A generic overview of different variables or factors necessary to build such business collaboration are presented and discussed critically in this study.
\end{abstract}

Keywords: Business community, non-hierarchical collaboration, business competition, virtual organization, case study.

\section{Introduction}

In order to achieve competitive advantage, non-hierarchical collaboration among firms has nowadays become very important, especially for SMEs. This type of collaboration is considered as a key issue to cope with markets demands and stay competitive in the market segment through the sharing of competencies and resources among SMEs [1]. Firms need to improve their competences significantly through new business models, up-to-date strategies, technological capabilities and processes with a view to be successful in the market. In such business environment, firms are increasingly restructuring their internal operations, information systems, production processes and collaboration strategies with other firms in complex value chains, business ecosystems, which extend globally [2]. These collaborative business networks are complex entities, where proper understanding for designing, implementing and managing is needed, with a view to business success and for better decision making [3]. This collaboration provides value creation processes for firms in terms of developing 
Virtual Organization Breeding Environment (VBE) or Virtual Organization (VO), which are the long term and short term strategic alliances respectively with specific opportunities/goals [4, 5].

Business collaboration can be both hierarchical and non-hierarchical based on the objectives, requirements and the controlling power of the participating partners. In hierarchical collaboration, firms are generally connected following a vertical type of information exchange, where the collaborations are considered as rigid and with strong control on each other. Whereas, in non-hierarchical collaboration, firms are connected with each other in a horizontal power sharing where firms enjoy similar level of controlling on each other. This non-hierarchical collaboration is more flexible and operates in a more agile way than hierarchical ones. Mostly, SMEs collaborates hierarchically with big firms, whereas they collaborate with each other nonhierarchically. Large firms usually use economics of size as their competitive advantage, supported by large market channels, whereas small firms collaborate to compete in terms of flexibility and focus on totally different market segments than their larger competitors. The key problem is that in hierarchical networks, larger companies control the whole process and keep most of the added value, forcing SMEs frequently to compete based on price.

In literature various approaches/methodologies are initiated to provide for collaborative business networks. Afsarmanesh and Camarinha-Matos [6] defined a collaborative framework ARCON (A Reference model for COllaborative Networks) mainly for enterprise modeling that provides a comprehensive environment for modeling a variety of collaboration forms, namely VBE, VO, Professional Virtual Community, and Virtual Team. Romeo et al [7] developed VBE instantiation methodology with the views to identify the required components and functionalities necessary during the successful creation of a breeding environment for achieving the collaborative goals. Paszkiewicz and Picard [8] proposed a collaborative methodology within ECOLEAD project referred as Virtual Organization Breeding Methodology (VOBM) that defines the structure of VBE and VO architectures in a service-oriented environment, as well as an architecture development method for virtual organizations (ADM4VO). A metamethodology concept articulated by Noran [9] can be defined as a method on how to produce methods for various collaborative networked organizations (CNOs) or $\mathrm{CNO}$ types whereas; Hoffner et al. [10] proposed a concept of typed domain, which helps establish successful relationships between partner organizations and simplify the negotiation between potential partners.

The growing rate of networking among SMEs reflects a catch-up of technology that considers as one of the competitive advantages for them. Mytelka [11] states that a firm's competitiveness may be in fact determined more by its external network than its size. In less hierarchical collaboration SMEs overcome their economic of size and find the proper market niche, especially in complex products with low volume and high variety. Those products are frequently engineer-to-order (ETO) and/or assembleto-order (ATO) products and the manufacturing of such products is basically project based. These products are highly customer-oriented and individually tailored according to customers' own preferences and choices. To cope with such challenges in product development, firms adopt external support in a form of non-hierarchical collaboration to exchange valuable information and resources between each other to fulfill market 
demands and earn more revenue. Isolation nowadays kills firms, especially for SMEs which affects negatively over them in terms of innovation and prosperity.

\section{Research Methodology}

In this research, it was adopted a case study approach with the view to understand the formation of non-hierarchical collaboration among SMEs. Various data was collected from six companies belonging to three case networks in different industrial sectors namely, textile and apparel, footwear and machine tools. Two companies from each industrial sector were identified and selected based on their product offerings, market shares, annual turnovers and number of employees. All the companies were leaders in their corresponding market segments and in small/medium sized in terms of revenue earnings. The objectives of these multiple case study were to elaborate and positioning of non-hierarchical collaboration trends among different business communities and investigate the suitability and/or applicability of this methodology.

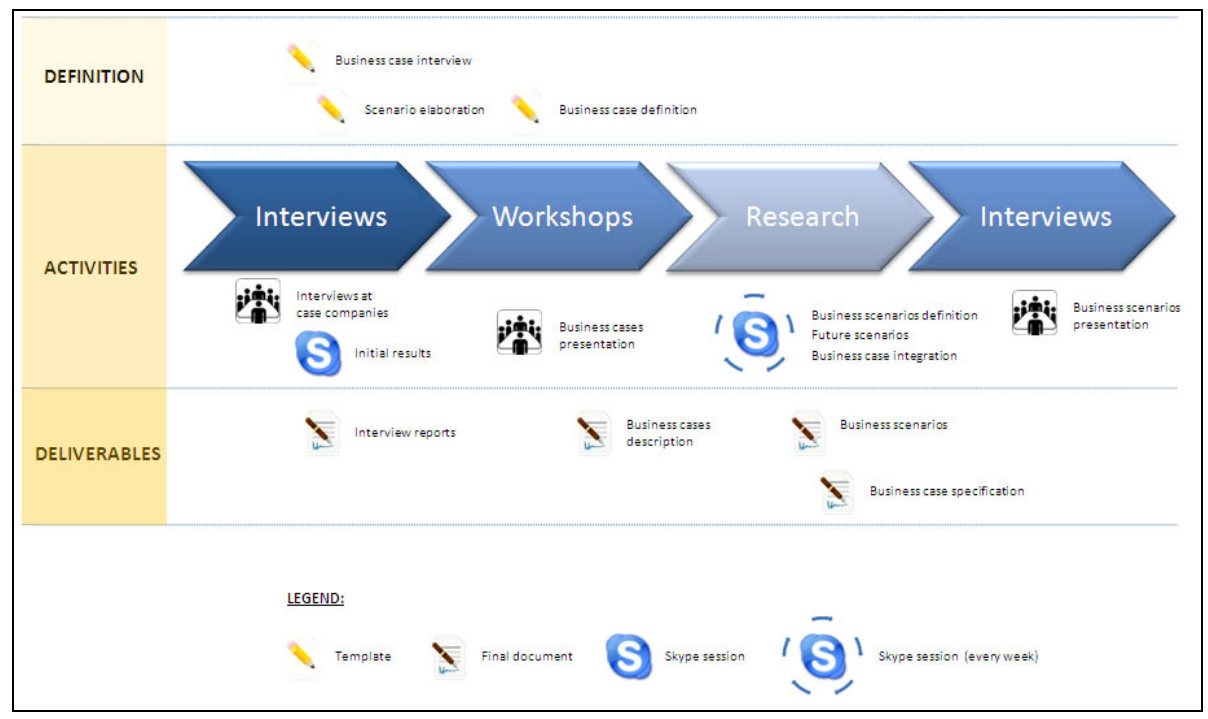

Fig. 1. Business case definition workflow

The study was conducted through structured interviews with management personnel of the case companies in order to collect and compare the available information such as; their current products, existing market shares, available resources, potential partners and their selection criteria, networking practices and specific business constraints, technologies implemented and constraints. Three specific steps were adopted to conduct this study such as: Definition (creation of templates to be used on interviews and questionnaires), Activities (activities and tasks performed to achieve the desired findings) and Deliverables (documents produced by researcher and business partners.) Figure 1 presents the three internal stages as described. 
The definition stage included the creation of templates and definition of workflows for a complete data acquisition. The templates for the business case interview questionnaires were followed as guidelines for each case company and can be presented as follows:

(a) Background information (Business objectives; Market targets; Products; Major customers; Major suppliers/partners);

(b) Current major production processes and supply network strategies;

(c) Current status and practices of collaboration or networking;

(d) Future needs for collaboration and associated supporting tools, regarding Business methodology, Business processes, IT decision support tools.

The activities phase included all the methods used to analyze and gather data (based on the previous templates defined). Applying a constant abstraction on the data provided, a deep study has been made to match the first "common" needs for the six companies and a brainstorm (with all partners) was organized, resulting on a workshop. The result of this meeting was a full description of the business cases and acted as a starting-point to a deep benchmark research about current scenarios on other companies and a first study of possible business scenarios (which could fulfil business companies' needs). A new set of interviews was performed with the business case's managers to specify relevant business scenarios. The deliverables phase concerns all the documents produced related to the previous stage.

\section{Business Scenarios in SMEs}

The objective of defining future business scenarios is to analyze activities that can create higher value for the potential customers and provide increased competitiveness for SMEs. In non-hierarchical networks, it is therefore needed to offer high value products and services through direct involvement of partners, both up and downstream in the value chain, including customers, suppliers, distributors, etc. For such non-hierarchical collaboration environment, SMEs could pursue product and service innovation, offer high value products and services, to enlarge their value chains and decision power related to production and delivery. In any business scenario trade-off between many different dimensions like flexibility, time, cost and quality across the entire value chain has to be taken into consideration when defining how to implement these networks.

Before implementing multiple business scenarios such as expansion of market segments, achieving cost competitiveness, quality, manufacturability, production timing, supply chain flexibility etc for collaboration in non-hierarchical networks, SMEs have to identify and prioritize the most valuable and important scenarios for target implementations. They need to examine these multiple scenarios before approaching any form of networking strategy. Both the benefits and obstacles to implement those business scenarios in SMEs need to be identified. Three major disciplines that use business scenarios are strategic management, human-computer interaction and software and systems engineering with a view to deal with description of current and future realities [12]. In this research, we studied the approach of six European SMEs belonging to 3 industrial sectors, in order to define business scenarios for collaboration in non-hierarchical networks which are displayed in Table 1 [13]. 
During this research most important categories of network lifecycle have been defined as: Build (which includes scenarios for companies with common business goals and are supported by a common ICT platform for sharing information and getting known to each other), Qualify (including scenarios for qualification of partners in the community), Form (including scenarios during which specific partnerships are created for a business opportunity), Operate (which include scenarios for design /production implementation), dissolve. The scenarios identifies with the companies have been classified according to the networking phase to which they belong. The first four scenarios include the establishment of the business community (Virtual Organization Breeding Environment), inviting companies into building the community and scenarios 5, and 6 qualifying the potential partners of the community. Scenarios 7, 8, 9, and 10 are grouped together to form the $\mathrm{VO}$ with a view to achieve design, engineering and communication systems among partners, while scenarios 11, 12, 13, 14, 15, 16, and 17 are involved in the operational phase of the virtual organization. Scenario 18 outlines the dissolution mechanism of the virtual organizations when certain missions of the business community's are fulfilled within specific time limit.

Table 1. Generic business scenarios of the six case companies

\begin{tabular}{|c|l|c|}
\hline $\begin{array}{c}\text { Scenario } \\
\text { no. }\end{array}$ & \multicolumn{1}{|c|}{ Description of the scenario } & $\begin{array}{c}\text { Networking } \\
\text { Phase }\end{array}$ \\
\hline 1 & A company wants to participate in a business community & Build \\
\hline 2 & $\begin{array}{l}\text { A community member invites a company to participate in the } \\
\text { business community }\end{array}$ & Build \\
\hline 3 & Selection of potential partners for a new business line & Build \\
\hline 4 & Knowledge sharing within the network & Build \\
\hline 5 & Qualification of potential partners for a new business line & Qualify \\
\hline 6 & Select partners for a specific market opportunity & Qualify \\
\hline 7 & Design a new collection (catalogue) & Form \\
\hline 8 & Developing market research & Form \\
\hline 9 & Standardize communication with customers & Form \\
\hline 10 & $\begin{array}{l}\text { All processes of the company are concentrated in one and only } \\
\text { very simple ICT tool }\end{array}$ & Form \\
\hline 11 & Improve operations plan for an order & Operate \\
\hline 12 & Monitoring operations & Operate \\
\hline 13 & Reaction to an unexpected event & Operate \\
\hline 14 & Evaluating the network performance & Operate \\
\hline 15 & Adjusting production capacity to meet expected demand & Operate \\
\hline 16 & Creating a global production schedule for an order & Operate \\
\hline 17 & Subcontracting & Operate \\
\hline 18 & Network dissolution & Dissolve \\
\hline
\end{tabular}

There are also several scenarios related with knowledge transfer and trust building. The result from different market research, community as business promoter, standardizing communication and technical workshops require commitment and interaction from the partners and link the partners closely together. It's expected a strong commitment and trust among business partners to fulfill various scenarios which are 
beneficial to fulfill their business targets. The practice of planning business scenarios encourages SMEs to envision plausible future prospects and consider how to take advantage of opportunities and avoid potential threats.

\section{Business Partners and Non-hierarchical Collaboration}

\subsection{Potentials for Business Partners}

Manufacturing firms especially SMEs are forced to cooperate even sometimes with their core competitor in order to faster access to new business opportunities and new markets. With the views for successful production planning and achieving certain business objectives, SMEs need specific support to find the right partners (according with several criteria) as well as their qualification as future business partners. Business partners can be defined as a commercial entity with which another commercial entity has some form or collaboration or alliance. Partners can overcome business challenges: attain business goals, access resources (expertise, know-how etc.), which are generally outside the scope of a single firm. Through partnering SMEs achieve global presence, reduce risks, gain cost benefit, increase the utilization of assets, allows achieving economies of scale, etc [14].

Crowley and Karim [15] proposed co-operative partnership using diagrams indicating permeable boundaries and indicating a cell-like organization. They conceptualized that partnerships involved four dimensions: (i) adversarial (perceived by the involved parties as a win/lose situation and leading to more formal litigation); (ii) guarded adversarial (relationships that strictly adhere to and are interpreted by the contracts); (iii) informal partners (understand and cooperate with parties with fewer disputes) and (iv) project partners (equal partners working co-operatively to pursue a common set of goals). Angulo et al. [14] presented a simple but operational model for selecting the potential partners, where the partners are selected from a Virtual Enterprise Breeding Environment. Bittencourt and Rabelo [16] proposed an Analytic Hierarchy Process (AHP) method considering SCOR model as the base metrics to the selection process of the most suitable enterprises (partners) in a given business opportunity.

In long term partnerships, SMEs commitment is important to exchange detailed and reliable information about product, capacity, demand and orders with customers and suppliers, improving planning and control processes and material flow and evolving to full collaboration within a network. A critical evaluation among partners are therefore required before proceed any kind of collaboration with each other in order to achieve several business goals. Several important critical factors for partnerships are needed to be analysed to match the common requirements among partners. What came out from the analysis with the companies in the project research is that: selection process of business partners is not an easy task but a thorough understanding of the potential partners' business information is required.

\subsection{Critical Success Factors of Partnerships}

Business collaboration is the most innovative development in delivering a project efficiently. It provides a sound basis for achieving a win-win situation among partners. The fundamental principles of partnering are trust, commitment, communication, 
respect, and equality. It includes the appropriate consideration of the interest of all parties involves in the collaboration process at every level and aiming to build trust among the parties involved in a contract. In business collaboration, there needs to evaluate critical success factor among potential partners in order to achieve specific business goals.

Critical success factors of non-hierarchical collaboration can be defined as those factors that determine the success or failure of a firm. These factors are measured by comparing the value of several predefined variables (noticed or unnoticed) in successful and unsuccessful partnerships. General measures of success in partnerships (satisfaction and sales volume in the relationship) can be stated as communication quality and participation, conflict resolution techniques, coordination and trust and a partnership attributes of commitment [17].

According to the results of the business process analysis hold on during this research, the key success factors for non-hierarchical collaborative business networks can be summarized as follows.

- Development of trust between participants in the business community

- Development of change management programs to reduce the natural reaction to change from internal personnel, at different levels of the organization

- Well defined, clear and formalized roles for all partner companies

- Formalized and standard collaboration process

- Availability of shared knowledge, competencies and experiences with partner companies

- Human resources with the required technical skills and collaboration experience

- Shared values between the companies in the business community

- Enough financial resources for the defined strategic objectives

- The ICT support tools to be made availability to use by the companies at different levels involved

As a result, the development of regional or sectorial Business Communities, where trust can be built and communication streamlined will be critical for the fast and efficient creation of these business networks. There needs to be special care when considering the success factors as the success or failure of any kind of collaboration mostly depends on the outcomes of these factors. These factors or variables vary from one collaborative network to another network depending on its main objectives.

\section{Empirical Study: Business Cases}

The companies of the case studies produce complex and/or customized products, with low volumes and high product varieties in their production processes. Complexity can be given by different factors such as: in the case of machine tools the product itself is very complex and requires the collaboration of many different factors for many months; in case of footwear and apparel companies the complexity is given by the variability of the product to be managed concurrently, every season each company can produce/manage 3-400 different product models which needs to be designed, industrialized and produced in a collaborative way. The descriptions of the case companies are 
summarized in Table 2 in terms of country, business field, number of employees and annual turnover.

Table 2. Business information of the six case companies

\begin{tabular}{|c|c|c|c|c|}
\hline Company & Country & Business field & Number of employees & Turnover \\
\hline Case A & Portugal & Textile and apparel & 800 & $50 \mathrm{M} €$ \\
\hline Case B & Portugal & Textile and apparel & 23 & $5 \mathrm{M} €$ \\
\hline Case C & Italy & Footwear & 10 & $0.5 \mathrm{M} €$ \\
\hline Case D & Italy & Footwear & 35 & $8.5 \mathrm{M} €$ \\
\hline Case E & Spain & Machine tool & 6 & $1.8 \mathrm{M} €$ \\
\hline Case F & Spain & Machine tool & 150 & $23 \mathrm{M} €$ \\
\hline
\end{tabular}

During Business Scenarios analysis hold with the six case companies and comparing the results of the analysis with the most important collaborative models in literature, it is observed that companies are laggings of proper tools or methodologies to select, establish and communicate among potential partners in their business communities. There are also misconceptions and confusions for selecting potential partners and in the definition of the type of collaboration they can establish for their business success. For complex products manufacturing it is especially important the integration between design and partner selection. Building trust among potential partners seems the highest level of concern for this collaboration. There are also fears of confidentiality of information flow among partners and type of collaboration they are looking for.

In such business environments, it looks very comfortable for the companies to build up non-hierarchical collaboration, where companies could support each other in a horizontal relationship rather than vertical dependency as in hierarchical network. In such non-hierarchical relationships, case companies could share their resources, valuable information and value added activities among them in order to be benefited in the market place. This trust building influences them for potential innovation in their product development processes and capture new market shares for business expansion. From this study, it is noticed that although the case companies have some collaboration with other business networks it doesn't exist any IT based tools or methodologies to track the real-time information, which could ensure the safety and confidentially of valued information exchange among partners.

When in the need to create a specific Virtual Organization within a Business Community, most common way to communicate with their partners is done by phone calls, faxes or emails. Phone discussions are used for non-formal tacit knowledge exchange. Written emails are more formal to finalize the discussion started in phone. Both methods have the lack of sharing the agreed decisions inside the companies or even with other partners in the same virtual organization, also by the unstructured data result provided by these types of communication. Therefore, the research has started in defining a standard procedure for knowledge sharing for the case companies involved in collaborative networks. Some possible ways to improve collaboration in non-hierarchical networks can be: to standardize the communication roles using RASCI-model. Another way to share the discussion would be to share a pin-code for the information and every partner who has the pin-code could access to the available information. 


\section{Results and Discussions}

To cope with turbulent business environment and meet customers' demands efficiently and effectively, there is no ways to be collaborative among SMEs rather than stay isolated from the business community. This collaboration is very much influential for SMEs, which are especially forced to produce products with different degrees of complexity such as textile and apparel, footwear, machines tools etc., creating higher product varieties, lower or unstable demand volumes. Business collaboration can contribute by developing production methods and new product features through exchanging valuable information among partnering companies. This methodology might attract SMEs for future developments in design for collaboration (DFC).

Exchanging emails and phone discussions are not enough for SMEs to collaborate. They should exchange documents using more controlled processes and adapt methodologies to share knowledge with trustable partners. The networking partners need social business solutions that are easy to use but still include the confidentiality aspect needed for business transactions. However, during the scenario collection process it has become obvious that the SMEs are acting in an ad-hoc world. The reason to prioritise an order might be for one partner the cash pre-payment and for the other the low season capacity level. The culture for sharing is not mature and the SMEs should get positive results that the collaboration gives more than takes. There is also need to enable not sharing critical knowledge, currently the partners are not sharing the information about the customer and price.

The research points out the high importance of promoting dynamic business communities as an enabler for the fast and efficient response to market opportunities. Various business scenarios that might be useful guidelines for SMEs in a nonhierarchical collaboration are presented. This structuring might be a valuable support for SMEs in a methodological approach and ICT-solution for guiding the network formation and partner qualification through sharing information among each other. This approach opens the platform for sharing required data in order to establish the collaborative network. The research presented in this paper provides specific support to find the right partners as well as their qualifications as future business communities. The project will develop tools for SMEs to select and qualify partners, build and collaborate within business community and enable online communication.

\section{Acknowledgement}

The authors would like to acknowledge the co-funding of the European Commission within NMP priority of the Seventh RTD Framework Programme (2007-13) for the Net-Challenge project (Innovative Networks of SMEs for Complex Products Manufacturing), Ref. CP-FP 229287-2.The authors also extend their thanks to the anonymous reviewers for their helpful comments and support.

\section{References}

1. Camarinha-Matos, L.M., Afsarmanesh, H., Ollus, M.: Ecolead and CNO Base Concepts. In: Methods and Tools for Collaborative Networked Organizations. Springer Science+ Business Media, LLC, Heidelberg (2008) 
2. Myers, J.: Future Value Systems: Next Generation Economic Growth Engines \& Manufacturing. In: Proceedings of the IMS Vision Forum 2006, Seoul, Korea, pp. 30-47 (2006)

3. Camarinha-Matos, L.M., Afsarmanesh, H.: A Comprehensive Modeling Framework for Collaborative Networked Organizations. J. Intell. Manuf. 18, 529-542 (2007)

4. Romeo, D., Galeano, N., Molina, A.: Virtual Organization Breeding Environments Value System and Its Elements. J. Intell. Manuf. 21, 267-286 (2010)

5. Romeo, D., Molina, A.: VO Breeding Environments \& Virtual Organizations Integral Business Process Management Framework. Information System Frontiers (ISF) 11, 569597 (2009)

6. Afsarmanesh, H., Camarinha-Matos, L.M.: The ARCON modeling framework. In: Collaborative networks: Reference modeling, pp. 67-82. Springer, New York (2008)

7. Romero, D., Galeano, N., Molina, A.: A Virtual Breeding Environment Reference Model and Its Instantiation Methodology. In: Camarinha-Matos, L.H., Picard, W. (eds.) Pervasive Collaborative Networks, pp. 15-24. Springer, Boston (2008)

8. Paszkiewicz, Z., Picard, W.: Modeling Virtual Organization Architecture with the Virtual Organization Breeding Methodology. In: Leveraging Knowledge for Innovation in Collaborative Networks, vol. 307, pp. 187-196. Springer, Boston (2009)

9. Noran, O.: Towards a meta-Methodology for Collaborative Networked Organizations. In: Virtual Enterprises and Collaborative Networks, vol. 149, pp. 71-78. Springer, Boston (2004)

10. Hoffner, Y., Field, S., Facciorusso, C.: The Typed Domain- a Recipe for Creating Virtual Enterprises. In: Virtual Enterprises and Collaborative Networks, vol. 149, pp. 53-62. Springer, Boston (2004)

11. Mytelka, L.: Crisis, Technological Change and the Strategic Alliance. In: Mytelka, L. (ed.) Strategic Partnerships and the World Economy, pp. 7-34. Pinter, London (1991)

12. Jarke, M., Bui, T.B., Carroll, J.M.: Scenario Management: An Interdisciplinary Approach. Require. Engng. 3, 155-173 (1998)

13. Carneiro, L., Kankaanpää, T., Almeido, R., Ferreira, P., Loichate, M., Pecina, M., Fornasiero, R., Zaniacomi, A., Chiodi, A., Rymaszewska, A.: Specification of Business Cases. Delivery D1.2. NetChallenge Project (2009)

14. Angulo, P.S., Martin, J.J.B.: Design and Implementation of a Multi-agent Framework for the Selection of Partners in Dynamic VEs. In: Leveraging Knowledge for Innovation in Collaborative Networks, vol. 307, pp. 341-348. Springer, Boston (2009)

15. Crowley, L.G., Karim, A.: Conceptual Model of Partnering. J. Mgmt. Engng., ASCE 11, 33-39 (1995)

16. Bittencourt, F., Rabelo, R.J.: A Systematic Approach for VE Partners Selection Using the SCOR Model and the AHP Method. In: Collaborative Networks and Their Breeding Environments, vol. 186, pp. 99-108 (2005)

17. Mohr, J., Spekman, R.: Characteristics of Partnership Success: Partnership Attributes, Communication Behavior, and Conflict Resolution Techniques. Strate. Mgmt. J. 15, 135$152(1994)$ 